\title{
Abnormal intraocular pressure control in systemic hypertension and diabetic mellitus
}

\author{
BILLIE I. WILLIAMS, ${ }^{1}$ W. S. PEART, ${ }^{1}$ AND E. LETLEY ${ }^{2}$ \\ From the ${ }^{1}$ Medical Unit, St Mary's Hospital, Praed Street, London W2 1PG, and the \\ ${ }^{2}$ Wellcome Research Laboratories, Beckenham, Kent
}

SUMMARY Retinal vein obstruction is a common complication of the retinopathy seen in patients with chronic hypertension. Previous studies have shown an abnormal control of intraocular pressure in response to changes of posture in patients with retinal vein obstruction. This paper describes the results of the investigation of the intraocular pressure response in 57 normotensive healthy adults and in 95 hypertensive patients, with a short study of 14 diabetic patients. Both hypertensive and diabetic groups showed abnormal responses. The possible significance of these findings as the expression of a fundamental anomaly shared by patients who develop either hypertension or diabetes is discussed.

In a previous communication we reported our finding that patients who have suffered a unilateral obstruction of a central or tributary vein have a bilateral defect in the regulation of their intraocular pressure when they are subjected to a change in posture. ${ }^{1}$ We found that, whereas our control subjects, who had not suffered a retinal vein obstruction, maintained a relatively constant pressure in both their eyes when they changed from the sitting to lying position, our patients showed a bilateral rise in pressure. Thus in the subjects we examined the mean rise in pressure recorded in a group of nonobstructed eyes was $0.6 \pm 1.2 \mathrm{mmHg}$, while that recorded in the eyes of patients with a central retinal vein obstruction was $1.8 \pm 2.4 \mathrm{mmHg}$ in the eye with the lesion and $2.6 \pm 2.3 \mathrm{mmHg}$ in the contralateral eye. Similarly, in the eyes of patients with a tributary vein obstruction the rise in pressure was $3 \cdot 1 \pm 2 \cdot 3 \mathrm{mmHg}$ in the obstructed eye and $2 \cdot 1 \pm 2 \cdot 2$ $\mathrm{mmHg}$ in the contralateral eye. (In this series of experiments both sitting and lying pressures were recorded after the subject had been in the relevant position for 15 minutes.)

We remarked on 2 aspects of our results which seemed to us to be of particular interest: (1) the response shown by our patients was in some ways similar to that shown by patients with primary open-angle glaucoma; (2) the abnormal response was shown by both eyes and not only by the eye with the obstructive lesion.

Correspondence to Dr B. I. Williams.
The first of these facts was interesting because there is a marked clinical association between openangle glaucoma and retinal vein obstruction, many patients with the latter condition developing this type of glaucoma in one or another eye. ${ }^{23}$ This suggested to us that eyes which develop open-angle glaucoma and those which develop venous obstruction may share a common defect which predisposes them to one or both of these conditions.

It seemed to us that the abnormal rise in pressure we had found must be due either to a defect in the outflow of fluid from the eye or to a relative increase of the intraocular contents (the globe being considered as a more or less inelastic container). We therefore proceded to compare the drainage potential of both eyes in a group of patients with a unilateral retinal vein obstruction using the Alcon Pneumatonograph. Our tonographic results showed no correlation between the value of the coefficient of outflow and the magnitude of the rise of intraocular pressure occurring in any eye when the patient changed to the lying position and no correlation between the relative values of the coefficients of outflow in any pair of eyes and the occurrence of the obstruction in one eye or the other. ${ }^{4}$ These results are in agreement with others, ${ }^{23}$ and we concluded that the postural rise of intraocular pressure is not dependent on impairment of drainage from the anterior chamber.

Our belief that this abnormal response to posture is the measure of an underlying anomaly which may predispose eyes to the development of a venous 
obstruction was strengthened by the second feature of our results to which we referred, namely, the abnormal response was bilateral. While we did not neglect the possibility that the behaviour of the contralateral eye might be explained as some sort of sympathetic effect resulting from changes in the eye which was the site of the lesion, it seemed more likely that the bilateral response might in fact represent such an underlying condition which, with time, had led to an overt obstruction in one eye.

In our original communication, we described retinal vein obstruction as a "major complication of the retinopathy seen in patients with systemic hypertension'. Certainly hypertensive patients form a large and distinct group of patients presenting with this lesion, and the retinal changes associated with chronic hypertension, namely, fat veins with a marked anteriovenous crossing phenomenon, are the background on which the picture of an obstruction so often supervenes.

We therefore decided to carry out the postural test on a small number of randomly selected patients from the hypertension follow-up clinic at St Mary's Hospital, London, as an initial study and to proceed to a larger investigation if the results suggested this was worthwhile.

\section{Pilot study}

We selected 12 patients, irrespective of age, sex, race, the aetiology, duration, or magnitude of their hypertension, and of whether they were receiving therapy; that is, we used the same criteria for selection as we applied to the selection of patients with venous obstruction in our original studies. We made an arbitrary definition of hypertension as that existing when any subject had a systolic pressure of $150 \mathrm{mmHg}$ or higher and a diastolic pressure of $90 \mathrm{mmHg}$ or higher on more than one occasion. We examined 6 men and 6 women. Their ages ranged between 29 and 60 years with a mean value of $45 \cdot 5 \pm 10 \cdot 6$ years. Their systolic pressure ranged between 110 and $230 \mathrm{mmHg}$ and their diastolic pressures between 82 and $145 \mathrm{mmHg}$, with a mean value of $164 \pm 42 \mathrm{mmHg}$ and $103 \pm 20 \mathrm{mmHg}$ (these pressures were recorded with the patients in the sitting position, the diastolic pressures being read at phase 4).

\section{Method}

Each subject was asked to sit quietly on a couch for 15 minutes, during which time the fundi were examined and a note was made of the state of the disc, veins, arteries, and arteriovenous crossings.
Two drops of oxybuprocaine $\mathbf{0} \cdot 3 \%$ and fluorescein $0.125 \%$ eye drops were then instilled in both eyes and the intraocular pressure measured with a Perkins hand-held applanation tonometer, the reading being taken when the insides of the half rings just touched in the diastolic phase. The right eye pressure was always measured first. Three rapid measurements were made and recorded for each eye. The subject was then asked to lie down (with one pillow under the head) and after 15 minutes the intraocular pressures were measured as before. All measurements were made by one observer (B.I.W.). Normally the 3 readings on the tonometer differed by no more than $0.5 \mathrm{mmHg}$ and frequently they were identical. In those unusual cases where there was more than $1 \mathrm{~mm}$ difference in the readings further rapid measurements were made until 3 readings differing by no more than $0.5 \mathrm{~mm}$ were obtained, and these were used.

\section{Results}

The mean rises recorded varied between 0 and 8.5 $\mathrm{mmHg}$ with an overall mean value for the group of $3.5 \pm 2.5 \mathrm{mmHg}$. Since these values are of a higher order than those we found for the groups of control patients in our initial experiments, we decided to carry out a larger and more detailed study of hypertensive patients.

\section{Main study}

\section{Protocol}

The information we wished to obtain from this study was as follows:

(1) Could we confirm our values for the control response to the postural test in a larger group of healthy normotensive adults? (2) Does the rise of intraocular pressure on lying in a group of randomly selected hypertensive patients differ from that in the control subjects? (3) Is there any relationship between the magnitude of the response to the postural change in any control or hypertensive subject and factors such as change in systemic arterial pressure, certain features observed on funduscopy, family history, personal medical history, or drug taking, including smoking and alcohol. (4) Is there any difference in the result of the postural test if the intraocular pressure is recorded at $0 \mathrm{~min}$, that is, as soon as possible after the subject lies down, as opposed to $15 \mathrm{~min}$ ? We designed our experiments with these questions in mind although our data were inevitably incomplete in certain respects for certain patients. 
Method

\section{CONTROL SUBJECTS}

This study was carried out at the Wellcome Research Laboratories, Beckenham. The subjects were all staff members who volunteered to have their intraocular pressure measured. All these volunteers received a preliminary examination by one of us (E.L.), who filled in a questionnaire with respect to age, sex, race, smoking and drinking habits, any tablets, pills, or medicines taken (including contraceptive tablets in the case of women), past and present medical history, and a family history which questioned specifically the occurrence of hypertension, coronary artery disease, stroke, renal disease, 'toxaemia' of pregnancy, diabetes, glaucoma, or other diseases. He measured their blood pressure (sitting position) and carried out a routine urine analysis to exclude proteinuria or glycosuria. As previously (in the pilot study) an arbitrary value of $150 / 90 \mathrm{mmHg}$ was taken as the dividing point, and any subject with either a systolic value or a diastolic value greater than these on more than one occasion was excluded from the control group. However, all volunteers were included in the study carried out by B.I.W., who had no previous knowledge of the results of this preliminary investigation by E.L. The study was therefore blind. Four volunteers were found to be hypertensive, 1 diabetic (with background retinopathy), and 1 had chronic uveitis with secondary glaucoma. They were excluded from the control group, the hypertensive subjects being transferred to the hypertensive group. We were left with 57 control subjects as a result of this procedure.

The values for sitting blood pressure found on the 2 occasions by E.L. and B.I.W. were compared by Duncan's multiple range test. The observations made by the 2 investigators were closely correlated.

Systolic blood pressure. Correlation coefficient $(p)=0.62, P<0.001$.

Diastolic blood pressure. Correlation coefficient $(\rho)=0.67, P<0.001$.

We examined 37 females and 20 males. Their ages ranged between 18 and 65 years with a mean value of $34 \cdot 5 \pm 13 \cdot 1$. Their mean arterial pressures were $114.7 \pm 11.5 \mathrm{mmHg}$ and $74.3 \pm 8.3 \mathrm{mmHg}$ (sitting position, diastolic pressure recorded at phase 4). Each subject was asked to sit quietly for 15 minutes on a couch. The arterial pressure was then recorded twice with a random zero sphygmomanometer. Two drops of oxybuprocaine $0.3 \%$ and fluorescein $0.125 \%$ were instilled in each eye, and the intraocular pressure was measured with a Perkins hand-held applanation tonometer by the same criteria as already described above. The subject was then asked to lie down from the sitting position (one pillow), and the intraocular pressure was once more measured in the same way, as soon as possible, that is, within the first minute. After the subject had been lying down for 15 minutes the systemic arterial and intraocular pressures were once more measured as before.

\section{HYPERTENSIVE SUBJECTS}

We examined 95 hypertensive subjects by a procedure precisely similar to that adopted for the controls. All the subjects included in the hypertensive group had a systolic pressure greater than $150 \mathrm{mmHg}$ or a diastolic pressure greater than $90 \mathrm{mmHg}$ recorded on more than 1 occasion.

We examined 46 females and 49 males. Their ages ranged between 18 and 80 years with a mean value of $49.3 \pm 14.4$ years. Their mean arterial pressures were $147 \cdot 5 \pm 24 \cdot 1 \mathrm{mmHg}$ and $98 \cdot 8 \pm 12 \cdot 8$ $\mathrm{mmHg}$ (sitting position, diastolic pressure recorded at phase 4).

\section{Results}

INTRAOCULAR PRESSURE (FIGS. 1 AND 2 AND TABLE 1)

(1) All the mean values for intraocular pressure fall within the normal range, irrespective of the position in which they were measured or the group to which the subject belonged, that is, $20 \mathrm{mmHg}$ or $<20$ mmHg. (2) There was no significant difference, within either group, between the right and left intraocular pressures irrespective of the position in which they were measured. (3) There was no significant difference between the mean intraocular pressure of the 2 groups when measured with the patient in the sitting position.

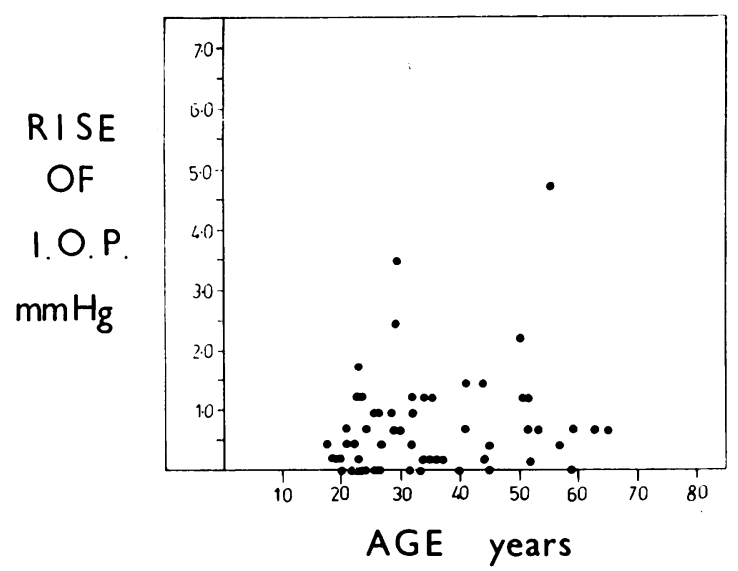

Fig. 1 Rise of intraocular pressure on lying-57 normotensive subjects. 
(4) The pattern of the rise of intraocular pressure associated with change of position was different in the 2 groups. In the control group the mean rise, when measured at $0 \mathrm{~min}$, was significantly higher than the mean rise measured at $15 \mathrm{~min}, 1.02 \mathrm{mmHg}$ compared to $0.60 \mathrm{mmHg}(\mathrm{P}<0.05)$. In the hypertensive group the mean rise at 15 min was significantly higher than that occurring at $0 \mathrm{~min}$, that is, $1.21 \mathrm{mmHg}$ compared to $0.61 \mathrm{mmHg}(\mathrm{P}<0.0005)$. (5) When the control was compared with the hyper-

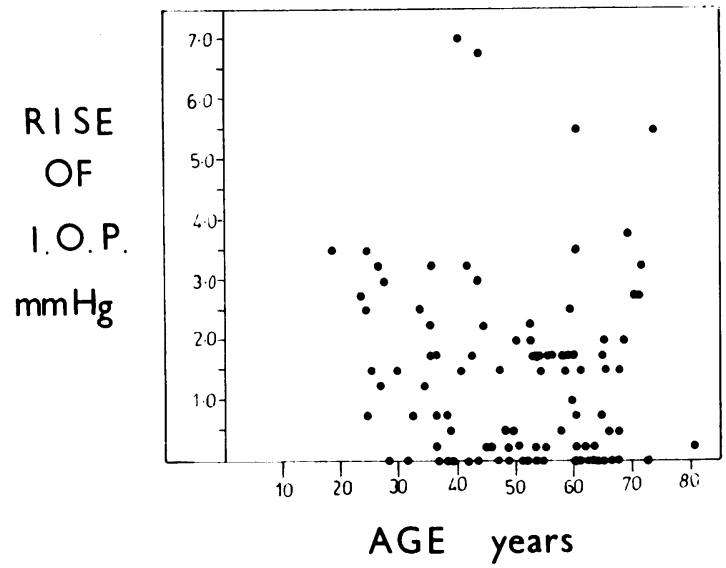

Fig. 2 Rise of intraocular pressure on lying-95 hypertensive patients.

Table 1 Intraocular and systemic blood pressure changes associated with change of posture

\begin{tabular}{|c|c|c|c|c|}
\hline \multirow{2}{*}{ Position } & \multirow{2}{*}{$\begin{array}{l}\text { Blood } \\
\text { pressure }\end{array}$} & \multicolumn{3}{|c|}{ Intraocular pressure $(\mathrm{mmHg})$} \\
\hline & & $\begin{array}{l}\text { Right } \\
\text { eye }\end{array}$ & $\begin{array}{l}\text { Left } \\
\text { eye }\end{array}$ & $\begin{array}{l}\text { Mean } \\
R+L \text { eyes }\end{array}$ \\
\hline \multicolumn{5}{|l|}{ Controls } \\
\hline Sitting & $\frac{114 \cdot 7 \pm 11 \cdot 5}{74 \cdot 3 \pm 8 \cdot 3}$ & $13 \cdot 9 \pm 2 \cdot 5$ & $14 \cdot 1 \pm 2 \cdot 8$ & $14 \cdot 0 \pm 2 \cdot 6$ \\
\hline Lying at $0 \mathrm{~min}$ & & $14 \cdot 8 \pm 2 \cdot 8$ & $14 \cdot 7 \pm 2 \cdot 9$ & $14 \cdot 7 \pm 2 \cdot 8$ \\
\hline Lying at $15 \mathrm{~min}$ & $\frac{111.4 \pm 9.6}{67.4 \pm 9.6}$ & $14 \cdot 6 \pm 2 \cdot 9$ & $14 \cdot 6 \pm 2 \cdot 9$ & $14 \cdot 6 \pm 2 \cdot 8$ \\
\hline Rise at $0 \mathrm{~min}$ & & & & $1 \cdot 0 \pm 1 \cdot 4$ \\
\hline Rise at $15 \mathrm{~min}$ & & & & $0 \cdot 6 \pm 1 \cdot 3$ \\
\hline \multicolumn{5}{|l|}{ Hypertensives } \\
\hline Sitting & $\frac{147 \cdot 8 \pm 24 \cdot 1}{98 \cdot 8 \pm 12 \cdot 8}$ & $14 \cdot 0 \pm 2 \cdot 5$ & $13 \cdot 9 \pm 2 \cdot 6$ & $13.9 \pm 2 \cdot 4$ \\
\hline Lying at $0 \mathrm{~min}$ & & $14 \cdot 4 \pm 2 \cdot 9$ & $14 \cdot 6 \pm 3 \cdot 1$ & $14 \cdot 5 \pm 2 \cdot 8$ \\
\hline Lying at $15 \mathrm{~min}$ & $\frac{147 \cdot 4 \pm 22 \cdot 2}{94 \cdot 0+14 \cdot 9}$ & $15 \cdot 1 \pm 3 \cdot 1$ & $15 \cdot 2 \pm 3 \cdot 1$ & $15 \cdot 1 \pm 2 \cdot 9$ \\
\hline Rise at $0 \mathrm{~min}$ & & & & $0 \cdot 6 \pm 1 \cdot 4$ \\
\hline Rise at $15 \mathrm{~min}$ & & & & $1 \cdot 2 \pm 1 \cdot 6$ \\
\hline
\end{tabular}

tensive group, the difference in the rise of pressure occurring at 0 min was not significant $(P \bumpeq 0.07)$, while the difference occurring at $15 \mathrm{~min}$ was significant $(P<0.005)$. This difference was tested after exclusion of hypertensive subjects who were not matched for age with control subjects, and the difference found was again significant $(P<0.05)$. It therefore appeared that this difference was not dependent upon age.

(6) In the control group the value for the rise of pressure occurring at $15 \mathrm{~min}$ was in extremely good agreement with that found for the similar group of control subjects in our original experiments, namely, $0.6 \pm 0.8 \mathrm{mmHg}$ (original group) and $0.6 \pm 1.3 \mathrm{mmHg}$ in the present study. ${ }^{1}$

SYSTEMIC ARTERIAL PRESSURE (FIG. 1)

Within each group there was no significant difference between the mean arterial pressures measured with the patient in the sitting and lying position. The mean arterial pressure was significantly higher in the hypertensive group, measured in both the sitting and lying positions respectively $(\mathrm{P}<0.0005$ and $\mathrm{P}<0.0005$ respectively).

We found no correlation between individual changes of systemic pressure (whether of magnitude or direction) and the magnitude of the rise in the intraocular pressure in association with the change from sitting to lying. This confirms our previous findings. ${ }^{1}$

\section{DRUGS}

We found no special relationship between any of the drugs taken by our subjects (including tobacco and alcohol) and the magnitude of the mean rise or intraocular pressure occurring with change of position.

MEDICAL HISTORY AND FAMILY HISTORY

Our results have not indicated any significant association of disease in the subjects or their relatives with the magnitude of the rise of intraocular pressure on change of position. However, this analysis was not deep and the numbers are too small for firm conclusions to be drawn.

\section{FUNDUSCOPY}

A detailed analysis of the relationship between the state of the disc, veins, arteries, and arteriovenous crossings of both eyes of all our subjects was performed. We failed to find a significant association between the mean rise of pressure at 0 min or $15 \mathrm{~min}$ and abnormality of any 1 of the above retinal variables within the hypertensive group. However, the presence of abnormal arteriovenous crossings was associated with a lower mean rise of 
pressure at 0 min than that found in their absence, and the correlation approached significance $(2 \mathrm{P}=$ 0.059). Conversely the mean values at 15 min were very similar in the presence or absence of this abnormality.

\section{Conclusions}

Our results have shown that a group of hypertensive patients as a whole behaved differently from a group of normotensive, healthy subjects with respect to control of intraocular pressure. With a change of posture from sitting to lying the hypertensive patients showed a significantly higher mean rise of intraocular pressure after 15 minutes in the lying position. In this respect their behaviour resembles that of patients who have suffered a unilateral obstruction of a central or tributary retinal vein. In the latter group, therefore, such a rise of pressure at 15 min cannot be the result of retinal vein obstruction, but must be due to factors which are in operation before obstruction occurs.

The greater rise of pressure at $0 \mathrm{~min}$ in the normal subjects did not achieve significance but did show a trend which is interesting and worthy of further study, particularly as the rise of pressure occurring in glaucomatous eyes has been recorded as soon as the subject lies down, or at 2 minutes. ${ }^{5}$

Reference to Figs. 1 and 2 shows that while the mean rise of pressure of hypertensive patients as a group may be higher than that of normotensive subjects, all hypertensive patients do not behave in a similar way. In $41 \%$ the rise of pressure was less than $1.9 \mathrm{mmHg}$ (mean + SD). Further, those who showed rises greater than this did not appear to fall into any particular age group: rises greater than the mean + SD occurred in patients as young as 18 years and as old as 70 years. This would suggest that the abnormal rise in pressure is not the result of the hypertensive process at work over a period of time but rather an anomaly which predates it in some hypertensives. If this is so, we may be dealing with an abnormality which, being present in only some subjects, is of importance as an indication of those hypertensive patients likely to suffer a retinal vein obstruction.

\section{Addendum}

The belief that the abnormal intraocular pressure response is the result of underlying anomaly shown by patients who develop hypertension and glaucoma led us to investigate a small number of diabetic patients, since there is a considerable amount of clinical evidence to link hypertension, diabetes, and primary open-angle glaucoma. Thus, this type of glaucoma is more common in the diabetic than in the nondiabetic population, and diabetes is more often found in patients with an open-angle glaucoma than is the case in the general population. ${ }^{6}$ Both diabetes and open-angle glaucoma can be provoked or exacerbated by the administration of glucocorticosteroids, and both groups of patients show abnormally high rises of intraocular pressure in response to the administration of topical steroids. ${ }^{7}$

Diabetics and hypertensives share the misfortune of vascular retinopathies, which have many features in common, including the development of venous obstruction, a complication which is not uncommonly associated with open-angle glaucoma, and, finally, in all these disorders we find strong evidence of the influence of inherited factors in their genesis. ${ }^{8-10}$

\section{Patients and methods}

We examined 14 patients of whom 4 were men and 10 women. Their ages ranged between 25 and 70 years with a mean value of $53 \cdot 36 \pm 13.3$ years. All patients had shown glycosuria together with random blood sugar levels $>12.0 \mathrm{mmol} /$ litre at some time, and we found that the duration of their disease varied between 4 and 30 years (in those cases where this could be established with reasonable certainty). All except 2 patients had presented with acute symptoms, the remaining 2 having disease of the maturity onset variety. According to our criteria (see above) 8 patients had a systemic hypertension, while 6 were normotensive, 11 had retinopathy associated with their diabetes, and 1 normotensive patient had unilateral retinal vein obstruction. All the patients except 4 were receiving oral therapy for their diabetes, the drugs used being chlorpropramide and glibenclamide. One patient was controlled by diet only, and 3 were being treated by combinations of soluble and long-acting insulin preparations. The hypertensive patients requiring therapy were being treated with various hypotensive agents, including methyldopa, debrisoquine, propranolol, hydrallazine, and the thiazide diuretics. One patient was receiving treatment with thyroxine.

We carried out intraocular pressure measurements on this group using the same protocol as was used in our pilot study of 12 hypertensive patients.

\section{Results}

The mean rise of intraocular pressure after the subjects lay down was $4.9 \pm 1.8 \mathrm{mmHg}$. This value is clearly significantly greater than that found in our control group (see above, $0 \cdot 6 \pm 1 \cdot 3 \mathrm{mmHg}$ ), being 
Table 2 Mean rises of intraocular pressure in 2 subgroups of diabetic patients

\begin{tabular}{|c|c|c|c|c|c|c|c|}
\hline \multicolumn{4}{|c|}{ Subgroup 1} & \multicolumn{4}{|c|}{ Subgroup 2} \\
\hline Patient & Sex & Age & $\begin{array}{l}\text { Mean rise } \\
I O P(\mathrm{mmHg})\end{array}$ & Patient & Sex & Age & $\begin{array}{l}\text { Mean rise } \\
\text { IOP }(\mathrm{mm} \mathrm{Hg})\end{array}$ \\
\hline 1 & $\mathbf{F}$ & 25 & $7 \cdot 0$ & 8 & $\mathbf{F}$ & 66 & 8.0 \\
\hline 2 & $\mathbf{F}$ & 33 & $6 \cdot 0$ & 9 & $\mathbf{F}$ & 54 & $6 \cdot 0$ \\
\hline 3 & $\mathbf{F}$ & 50 & $4 \cdot 5$ & 10 & $\mathbf{F}$ & 65 & 2.5 \\
\hline 4 & $\mathbf{F}$ & 47 & $3 \cdot 0$ & 11 & $\mathbf{F}$ & 65 & $5 \cdot 2$ \\
\hline 5 & $\mathbf{M}$ & 45 & 3.0 & 12 & $\mathbf{M}$ & 60 & 6.0 \\
\hline 6 & $\mathbf{M}$ & 50 & $3 \cdot 2$ & 13 & $\mathbf{F}$ & 70 & $3 \cdot 2$ \\
\hline 7 & $\mathbf{M}$ & 52 & $7 \cdot 5$ & 14 & $\mathbf{F}$ & 65 & $3 \cdot 5$ \\
\hline Mean & & $43 \cdot 2 \pm 10 \cdot 2$ & $4.9 \pm 1.9$ & & & $63 \cdot 6 \pm 5 \cdot 1$ & $4.9 \pm 1.9$ \\
\hline
\end{tabular}

somewhat greater than the value found for our pilot study of 12 hypertensives (see above, $3 \cdot 5 \pm 2 \cdot 5$ $\mathrm{mmHg}$ ). This study of a small group of diabetics therefore suggests very strongly that an inability to control the level of intraocular pressure with change of posture (from sitting to lying) is present in diabetics as well as hypertensives. Furthermore, it would seem that this abnormality is not determined by the presence of the coexisting systemic hypertension in $\mathbf{8}$ of our patients, since an analysis of the group has shown that the mean rise of intraocular pressure by the 6 normotensive diabetics was $4.7 \pm 1.8 \mathrm{mmHg}$, while that shown by the 8 hypertensive patients was $5.0 \pm 2 \mathrm{mmHg}$, and these figures are not significantly different.

It will be noted that the average age of the 3 groups of patients we have studied is 34.5 years for the control subjects, $49 \cdot 3$ years for patients with hypertension, and 53.3 years for patients with diabetes mellitus. However, we do not believe that the abnormal rises of intraocular pressure associated with change of posture seen in our hypertensive and diabetic subjects are dependent on this age difference for the following reasons.

(1) Within the hypertensive group patients showing rises of intraocular pressure greater than 1.9 mmHg (mean + SD for control subjects) when measured at 15 minutes did not fall into any particular age group, such rises occurring in patients as young as 18 years and as old as 70 years (see above and Figs. 1 and 2).

(2) The mean difference in the rise of intraocular pressure occurring in the control and hypertensive groups was tested statistically to establish whether the greater rise shown by the latter group was related to the fact that the average age of these patients was higher than that of the control subjects. Comparison of the mean rises of pressure in age-matched sub- jects from these 2 groups again proved to be statistically significant $(\mathrm{P}<0.05)$ (see above, Result 5 of Main Study).

(3) The diabetic group tested was relatively small but the age range was considerable, i.e., from 25 years to 70 years. As with the hypertensive patients high rises of intraocular pressure occurred in subjects at both ends of the age scale. Thus in our 2 youngest diabetic patients, aged 25 and 33 years, the rises of intraocular pressure were 7.0 and 6.0 $\mathrm{mmHg}$ respectively, while 2 of our older patients aged 66 and 60 years had rises of 8.0 and $6.0 \mathrm{mmHg}$.

To test the significance of the age factor in this small number of subjects we divided our 14 diabetic patients into 2 groups such that the first group contained the 7 youngest and the second group the 7 oldest patients. Comparison of the mean rises of intraocular pressure found in the 2 groups showed no significant difference despite the difference in mean ages; that is, the mean rise found was $4.9 \pm 1.9$ $\mathrm{mmHg}$ in the younger group and $4.9 \pm 1.9 \mathrm{mmHg}$ in the older group, though the mean ages were $43 \cdot 2 \pm 10 \cdot 2$ and $63 \cdot 6 \pm 5 \cdot 1$ years respectively (see Table 2).

We therefore believe that this abnormality is not age-related and may be the measurement of a fundamental defect linking hypertension, diabetes mellitus, and primary open-angle glaucoma.

We gratefully acknowledge the support by the Wolfson Foundation and thank the staff of the Wellcome Research Laboratories, Beckenham, where a great deal of this study was carried out. Their very valuable co-operation was much appreciated.

\section{References}

1 Williams BI, Peart WS. Effect of posture on the intraocular pressure of patients with retinal vein obstruction. Br J Ophthalmol 1978; 62: 688-93. 
2 Bertelsen RO. The relationship between thrombosis in the retinal veins and primary glaucoma. Acta Ophthalmol (Kbh) 1961; 39: 603-13.

3 Vannas S, Tarkkanen A. Retinal vein occlusion and glaucoma and its prognostic significance. $\mathrm{Br} \mathrm{J} \mathrm{Ophthalmol}$ 1960; 44: 583-9.

4 Williams BI, Peart WS. Retinal vein obstruction and intraocular pressure: abnormal postural response independent of facility of outflow. Br J Ophthalmol 1979; 63: 805-7.

5 Krieglestein GK, Langham ME. Influence of body position on the interaocular pressure of normal and glaucomatous eyes. Ophthalmologica $1975 ; 171$ : 135-45.

6 Becker B. Diabetes mellitus and primary open angle glaucoma. Am J Ophthalmol 1971; 71 : 1-16.

7 Becker B, Shin DH, Cooper D. Primary open angle glaucoma and diabetes mellitus-histocompatibility antigens and parental history. Invest Ophthalmol Visual Sci 1976; 15: 954-7.

8 Becker F, Hahn KA. Topical corticosteroids and heredity in primary open angle glaucoma. Am J Ophthalmol 1964; 57: 543-51.

9 Armaly MF. The genetic problem of chronic simple glaucoma. Presented at the XXI International Congress of Ophthalmology, March 1970.

10 Rimoin DL, Schimke RN. Genetic Disorders of the Endocrine Glands. St Louis: Mosby, 1971 : 150-216. 